\title{
Li isotope analytical protocol and standard development using Secondary Ion Mass Spectrometry (SIMS)
}

\author{
CRISTINA TALAVERA ${ }^{1}$, JOHN CRAVEN ${ }^{2}$, NICOLA
} CAYZER $^{2}$, CHRIS HAYWARD ${ }^{2}$ AND IVAN FEBBRARI ${ }^{2}$

${ }^{1}$ King's Buildings

${ }^{2}$ The University of Edinburgh

Presenting Author: cristina.talavera@ed.ac.uk

Lithium isotope study in tourmaline and Li-rich minerals, such as spodumene, petalite and mica, from evolved magmatic systems has rapidly grown in the last decade fostered by the development of analytical techniques using MC-ICP-MS and SIMS. The resulting Li isotopic signatures have been used as a geological tool to trace the evolution of these evolved magmatic systems from the emplacement and magma differentiation, through magmatic-hydrothermal transition, to solidification and cooling [1, 2], uncover the protoliths of melts [3]; and together with B isotopes, to discern gem provenance [4].

One of the advantages of in situ microanalyses by SIMS is the spatial resolution required to measure $\mathrm{Li}$ isotopic ratios of different stages of mineral growth from an individual crystal and inherited core and rims in the same grain. However, setting a new analytical protocol by SIMS is quite challenging due to the difficulty of finding chemical and isotopically homogenous Reference Materials (RMs) which can subsequently be utilised as matrix-matched to unknown targets. A recent inter-lab research project has characterised three new tourmaline RMs for $\mathrm{Li}$ isotopic analyses and has provided a new analytical SIMS protocol for tourmalines [5]. Nonetheless, new RMs for this microanalytical technique still need to be identified for other important Li-rich mineral phases. Here, we present the results of our work on several potential RMs for spodumene and petalite as well as the optimal analytical protocol for the analysis of $\mathrm{Li}$ isotopes developed in the Cameca IMS 7f Geo and IMS 1270 from the NERC Ion Microprobe Facility.

[1] Marschall \& Jiang (2011), Element 7, 313-319. [2] Xiang et al., (2020), Lithos 376-377 (105753). [3] Deveaud, Millot \& Villaros (2015), Chemical Geology 411, 97-111. [4] Ludwig et al., (2011), Mineralogical Magazine 75, 2485-2494. [5] Wiedenbeck et al., (2020), Geostandard and Geoanalytical Research (Early view). 